\section{JSCN T \\ Journal of Sustainable Construction \\ Materials and Technologies}

\title{
Maps for Planning and New Services to Open New Marketing and Working the Road
}

\author{
Mehmet Fatih Altan ${ }^{\mathrm{a}, *}$, Ali Gür ${ }^{\mathrm{a}}$ \\ ${ }^{a}$ Istanbul Aydın University, Halit Aydın Kampüsü No:38, Sefaköy-Küçükçekmece, Istanbul, 34295
}

Manuscript Received October 31, 2018; Accepted December 3, 2018

\begin{abstract}
This study has been examined what can be done to achieve the best in the state road planning process. It needs to be improved an existing highway. And the result should be predicted and applied. General traffic needs to meet, eliminate, and the negative effects caused by traffic or changes in land use are the main topics of planning. Part of the Policies and Procedures describes the minimum requirements and processes used. The country presents the results of its regular plans to the public for the development team to offer a development outcome. Country Programs, Regional Programs and Global Program. These documents are to make their vision, direction and strategies functional in the Strategic Plan. The programs are implemented with projects that have annual work plans. Planning seems simple enough. However, the ideal project will be designed and the design objectives will be determined and their design will be determined. Reality is much more complex. Today, the city means to engage with community and regional planning. To translate a vision, technical expertise, political knowledge and financial understanding need to comply with a strategic action plan for tomorrow and today. In fact, thousands of local government agencies and planning agencies have adopted GIS tools as a means to bring together. While dealing with limited financing and personnel, progress is being made in line with requests. Costs relate not only to the funding of potential funders, but also to the benefits of an action to ensure climate and development assistance in the country. This study explains how to identify potential funders in evaluating or screening investment proposals. The costs and benefits of both the proposed activities and the in-country capacity needs are considered. It can focus on a single technology with a potential in a country or sector or with a larger scale, and pedestrian paths. The barriers based on the portfolio of priority technologies within the sectors may determine whether there are more than one common points.
\end{abstract}

Keywords: New zoning; Mapping;Planning and Implementation

\section{Introduction}

The first task is to define the scale context for technology propagation. Second, it is necessary to summarize the

\footnotetext{
* Corresponding author. Tel.: 4441 428-22807

E-mail address:mehmetaltan@aydin.edu.tr (M.F. Altan)

https://doi.org/10.29187/jscmt.2019.40
} 
barriers to distribution and dissemination for each technology and then the possible measures against them. The first two aspects of such projects should be based on the work completed in the previous steps of the process. For a project, the previously defined measures are made into a list of actions; they are then extended to a specific set of activities, that is, to a specific set of clusters that must be performed to perform an Action. When activities are defined, relevant stakeholders, namely those directly involved in implementing the project, have been identified. Here, it is also important to estimate a time period for each activity. Following identification, the project should anticipate the human and financial resources required for each activity.

Calculations are made, including the type of financing required and the potential sources of funding. Finally, a management plan is required for the project, including a reporting, risk management, corrective measures and contingency plans. Diffusion is necessary with the associated common benefits, such as providing or upgrading the infrastructure.

Motorways, state and provincial roads are planned by General Directorate of Highways and village roads are planned, built and maintained by the General Directorate of Rural Services. The planning, construction and maintenance of lower standard forest roads are carried out by the Ministry of Forestry.

\section{Materials and Methods}

The purpose of this study is; Planned settlement, security and energy saving by ensuring that our people have a better quality future and to set an example for future generations to plan a planned settlement and road map. The main purpose is to contribute to the economy of our country by providing energy saving and less use of foreign resources. At the same time, it is aimed to improve the quality of life and to reduce the stress on people and to stay away from worries.

It is necessary to summarize the minimum requirements to complete this work. While land use practice allows for flexibility and professional work, zoning analysis requires a special permit. Authorizations and land use applications are required. Turkey is a detailed solution to the Zoning certificates. The current zoning regulation is subject to conformity.

One purpose of this study is to ensure that each completed project includes the following practices:

- A number of concrete actions required for successful technology implementation in the country,

- An indicative investment offer that can be taken into account for funding for each technology.

Moreover, it is aimed to create important sources of information when preparing zoning budgets in order to progress planned in new zoning and road constructions.

Some requirements may be denied, because municipal units and city regulatory agencies, regional committees and more and more active people can make this more difficult. It is aimed to overcome this situation with correct planning and promotion. 
The project may be a program that trains local engineers to avoid a lack of skills to operate in another example of action to overcome public opposition to technology.

To provide solutions to the new problems of the existing urban planning system in Turkey is observed that enter into new initiatives. With this study, evaluating the characteristics of the existing planning system in Turkey aimed to investigate the potential to adapt to innovative planning approach. In this direction, which is the product of an innovative experiment in planning and more planning hybrid system applied in developed countries, it is important to detect the presence in Turkey.

In this context, first of all, the strategic planning approach that constitutes the components of the kav hybrid planning system and the characteristics of the regulatory planning approaches are examined with theoretical and conceptual dimensions. In this study, then the separation of strategic and regulatory features of the existing planning system in Turkey and used to identify the main character of the existing planning system. existing planning system in Turkey, although the policies implemented in time to stand closer to the regulatory planning approach and strategic features of the legal arrangements with the host state has become.

\subsection{Development plan}

Zoning is applied to the place of the building islands, their density and layout, paths and other information that will be based on the application detailing the cadastral situation on the plan plan is called zoning plan.

The plan, which shows the building islands, their density and order, roads and other information prepared by the institutions and organizations authorized by the municipalities, the governorships or special laws, is called the zoning plan.

The zoning plan, the master zoning plan in our legislation, the implementation zoning plan, the zoning plan, the revision zoning plan and the mentioned technical and legal documents.

\subsubsection{Nazim zoning plan}

It is a detailed plan which is prepared on the basis of a detailed report which is prepared to prepare the implementation zoning plans showing the general usage forms of the parts of the land on the approved maps, the main types of regions, the future population densities of the regions, the density of the structures and the solution of the problems of transportation systems and problems.

\subsubsection{Implementation zoning plan}

Approved on the current maps of the cadastral status, and prepared in accordance with the master zoning plan and the structure of the various islands, their density and order, the paths and the application will be the basis for the implementation of the implementation of the implementation stages and principles and other information that shows the details and 1 / It is a whole with its report prepared in 1000 scales.

\subsubsection{Development plan}

In case the existing plans are insufficient for the settled population or the need to open new settlements is determined and the boundaries are determined by the related administration, it is possible to construct the plan according to the plan construction rules. is a development plan that provides a whole with its report. 


\subsubsection{Revision development plan}

In cases where both the master and the application development plans do not respond to the need and the application is a problem; plan or all of a large part of the plan is achieved by renewing the plan construction techniques.

\subsection{Planned Placement Management Plan}

You need to improve the plan in an event management and make the event ranking good. Planning is the most important part of conducting a successful event. Event management covers all problems related to planning and how the management plan is planned.

Zoning analysis is required for specified special Authorization, authorization and certification actions. Turkey, especially in Istanbul's Zoning solution, applicants are informed of all actions for specific land use. These guidelines provide general guidance only. Depending on the characteristics of the project, drawings or information from the project team may be required. The scope of the application, in turn, requires exceptions or modifications of these rules. It is necessary to take into account the site map and project features.

Zoning Analysis is a description of what is proposed for what and what is offered. Therefore, analyzes should be presented in tabular form and should show all calculations for easy comparison. Information about when a proposed project will be implemented is included. The conditions that require further clarification of the project team are explained in advance.

Exceptions requiring Additional Content: There are situations where additional elements are needed to define the zoning analysis. The project team and management will determine the compliance of the proposed project with the applicable zoning regulations.

The zoning and road construction management plan should include:

- Key objectives and measures;

- Project plan, critical path and task list listing all tasks required for delivery

- Project budget;

- Schedule or worksheet (including contact list);

- Other details about the settlement plan and zoning;

- Traffic management plan;

- Security summary;

- Contracts with suppliers;

- Event promotion and training;

- Waste management plan;

- Emergency management plan including evacuation map;

- Risk Management Plan;

- Public liability insurance;

- Wet weather, contingency plan,

- First aid;

- Infrastructure and equipment list.

Each cross-section alternative in has two possible layouts. The desirable cross-section should be used whenever possible. If a physical restriction prevents the implementation of the desirable cross-section, the county can use the minimum. Use of the minimum cross-section should only take place after adequate justification has been presented and approved. The geometrics for the different road. 
Table 1. Rural Subdivision Cross-section geometrics

\begin{tabular}{|c|c|c|c|c|c|c|}
\hline \multirow{2}{*}{$\begin{array}{c}\text { Design } \\
\text { Elements }\end{array}$} & \multicolumn{2}{|c|}{ Connector } & \multicolumn{2}{|c|}{ Collector } & \multicolumn{2}{|c|}{ Local } \\
\hline & Desirable & Minimum & Desirable & Minimum & Desirable & Minimum \\
\hline $\begin{array}{l}\text { Design speed } \\
(\mathrm{mph})\end{array}$ & 60 & 60 & 55 & 50 & 45 & 45 \\
\hline $\begin{array}{l}\text { Avg. daily } \\
\text { traffic }\end{array}$ & $>1500$ & $>1500$ & $400-1500$ & $400-1500$ & $<400$ & $<400$ \\
\hline Pavement width & $24^{\prime}$ & $\begin{array}{c}24 ' \text {-striped at } \\
22^{\prime}\end{array}$ & $24^{\prime}$ & $22^{\prime}$ & $22^{\prime}$ & 22 \\
\hline Shoulder width & $8^{\prime}$ & 8 & 6 ' & 5 , & $4^{\prime}$ & 4' \\
\hline Shoulder type & $\begin{array}{c}4^{\prime} \text { paved } / 4^{\prime} \\
\text { rock }\end{array}$ & rock & rock & rock & rock & earth \\
\hline $\begin{array}{l}\text { Right-of-way } \\
\text { width }\end{array}$ & $100^{\prime}$ & $80^{\prime}$ & $80^{\prime}$ & $66^{\prime}$ & $66^{\prime}$ & $66^{\prime}$ \\
\hline Slopes & $6: 1$ & $4: 1$ & $4: 1$ & $3: 1$ & $4: 1$ & $3: 1$ \\
\hline Parking allowed & none & none & none & none & none & none \\
\hline $\begin{array}{l}\text { Stopping sight } \\
\text { distance }\end{array}$ & 570 & $570^{\prime}$ & $495^{\prime}$ & $425^{\prime}$ & $360^{\prime}$ & $360^{\prime}$ \\
\hline $\begin{array}{l}\text { Horiz. curve } \\
(\min )^{*}\end{array}$ & $1340^{\prime}$ & $1205^{\prime}$ & $965^{\prime}$ & $760^{\prime}$ & $500^{\prime}$ & 500 \\
\hline $\begin{array}{l}\text { Maximum } \\
\text { grade }\end{array}$ & $5 \%$ & $8 \%$ & $6 \%$ & $8 \%$ & $8 \%$ & $10 \%$ \\
\hline
\end{tabular}

Table 2. Divent and suburban cross-section

\begin{tabular}{|c|c|c|c|c|c|c|}
\hline \multirow[t]{2}{*}{ Design Elements } & \multicolumn{2}{|c|}{ Connector } & \multicolumn{2}{|c|}{ Collector } & \multicolumn{2}{|c|}{ Local } \\
\hline & Desirable & Minimum & Desirable & Minimum & Desirable & Minimum \\
\hline Design speed (mph) & 60 & 60 & 35 & 35 & 30 & 30 \\
\hline Avg. daily traffic & $>1500$ & $>1500$ & $400-1500$ & $400-1500$ & $<400$ & $<400$ \\
\hline Pavement width & 31 & 31 & $31^{\prime}$ & $26^{\prime}$ & $26^{\prime}$ & $26^{\prime}$ \\
\hline Right-of-way width & $100^{\prime}$ & $80^{\prime}$ & $80^{\prime}$ & 66 & $66^{\prime}$ & $60^{\prime}$ \\
\hline Parking allowed & none & none & one side & none & one side & one side \\
\hline $\begin{array}{l}\text { Stopping sight } \\
\text { distance }\end{array}$ & $570^{\prime}$ & $570^{\prime}$ & $250^{\prime}$ & $250^{\prime}$ & 200 ' & $200^{\prime}$ \\
\hline Horiz. curve $(\mathrm{min}) *$ & $1505^{\prime}$ & $1505^{\prime}$ & $420^{\prime}$ & $420^{\prime}$ & $300^{\prime}$ & $300^{\prime}$ \\
\hline Maximum Grade & $5 \%$ & $8 \%$ & $6 \%$ & $10 \%$ & $6 \%$ & $10 \%$ \\
\hline
\end{tabular}

\subsection{Road Planning}

Final engineering planning identifies the exact location of the road, the areas required for the motorway, the highway, the intersection points of private roads and other road solutions, pedestrian, bicycle traffic, public transport solutions and other detailed solutions. Negative traffic effects are prevented by good planning. As engineering planning solves all problems directly affecting landowners and other interested parties, it focuses on issues that will interact.

The road management has approved the final engineering plan, which gives the right to the ownership of the necessary space for the road. It may sometimes be necessary to make a revision plan for an approved engineering plan.

This process is similar to the original plan. As long as the effect of the change is not too small, the agreement with the land owners is sufficient. After financing is provided, highway construction can be started.

Negative impacts or adverse effects arising from the process traffic cannot be reduced sufficiently. Reasons to improve and build existing motorways include: 
- Increased mobility due to housing, travel, business and service developments.

- Providing better service to transportation needs and providing industrial and commercial activities.

- Increased mobility during working hours and increased use of cars in traffic in our country.

- Making roads more secure and reducing impacts on the environment resulting from traffic.

- Improving pedestrian and bicycle traffic and facilitating the travel of public transport.

(1) Widen paved shoulders to $5^{\prime}$ (min.) to provide on-rood bicycle occomodation. This will impact
ditch slopes ond/or right-of-woy width.
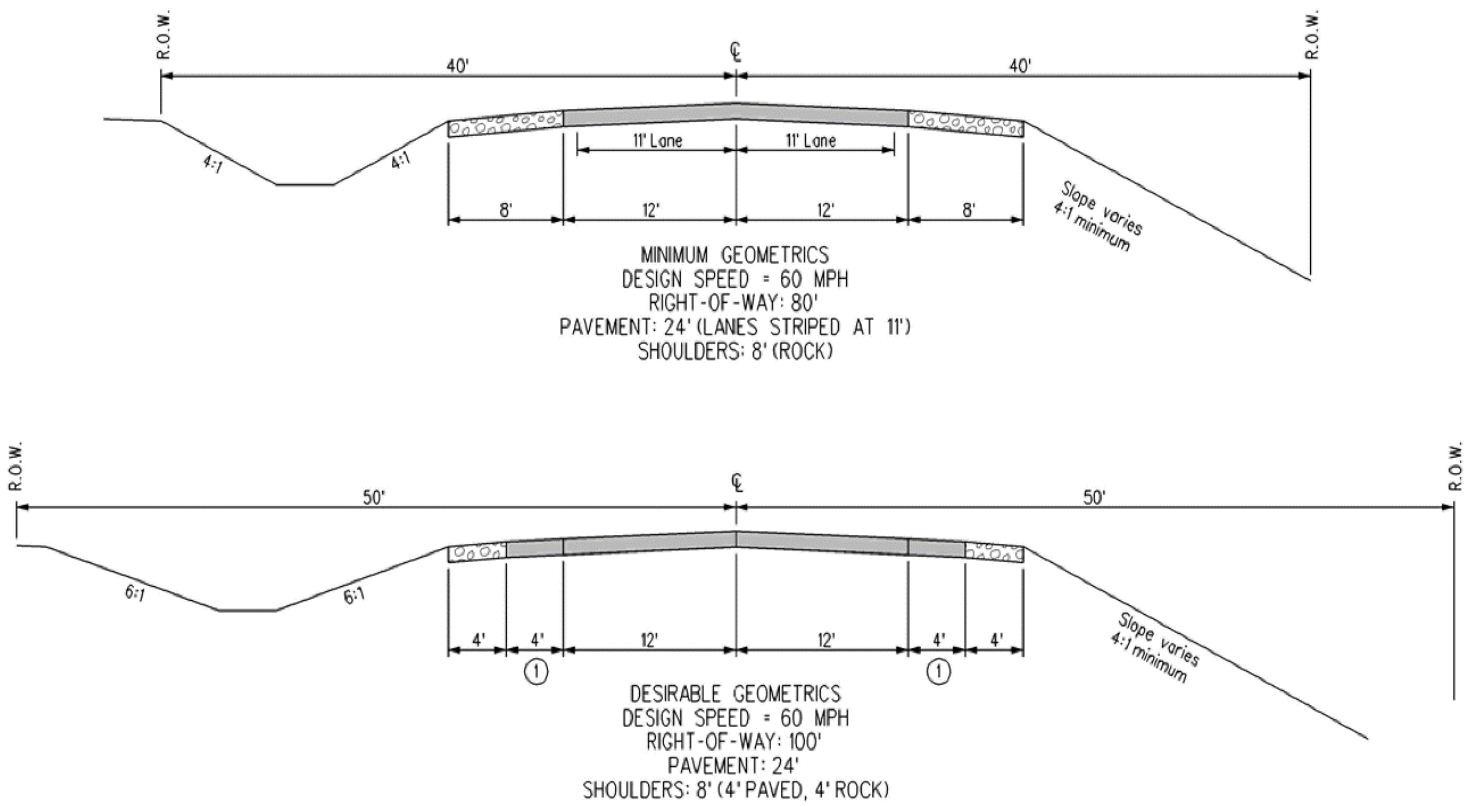

Figure 1.Rural Connector 


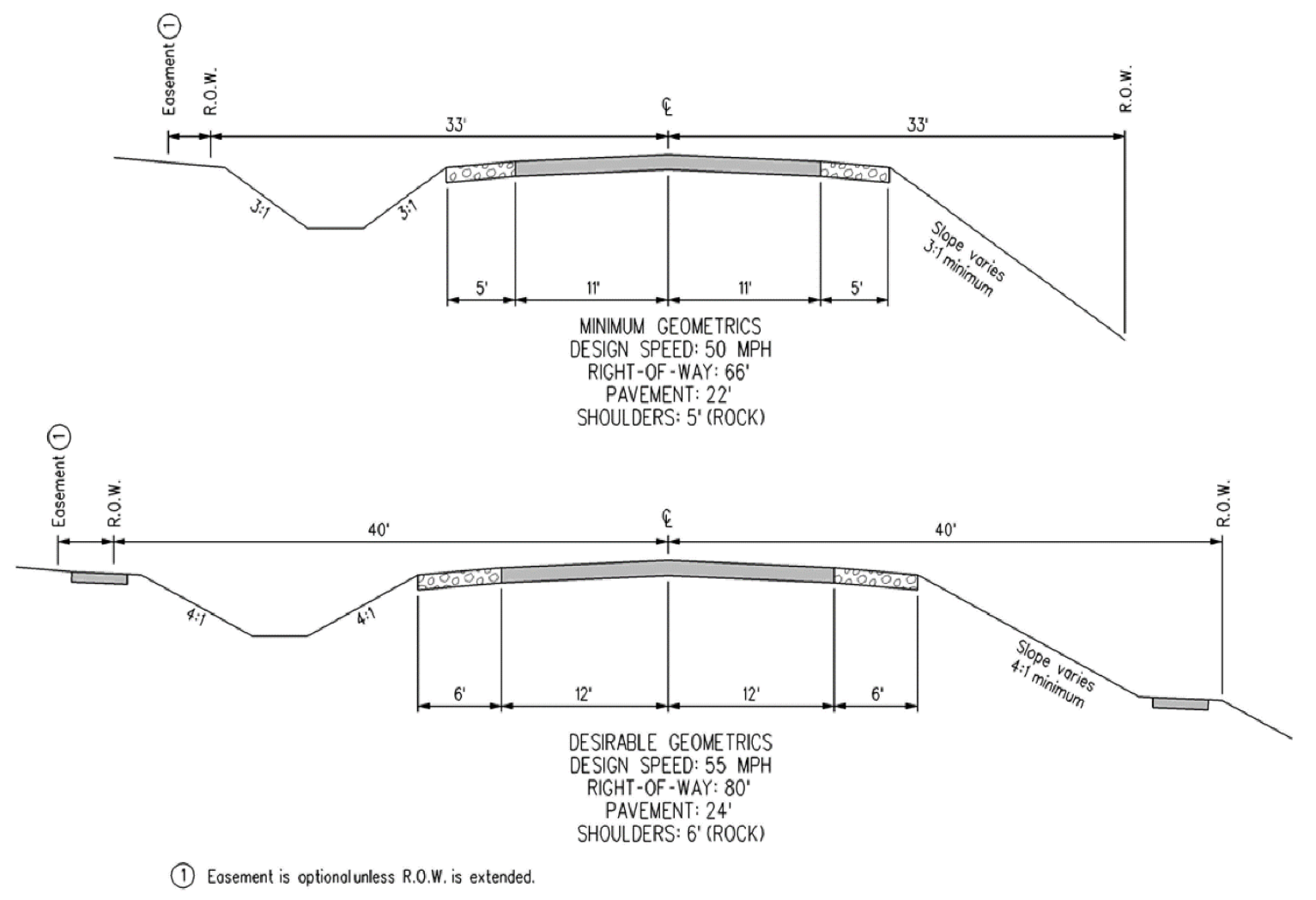

Figure 2 .Rural Collector Within Subdivision

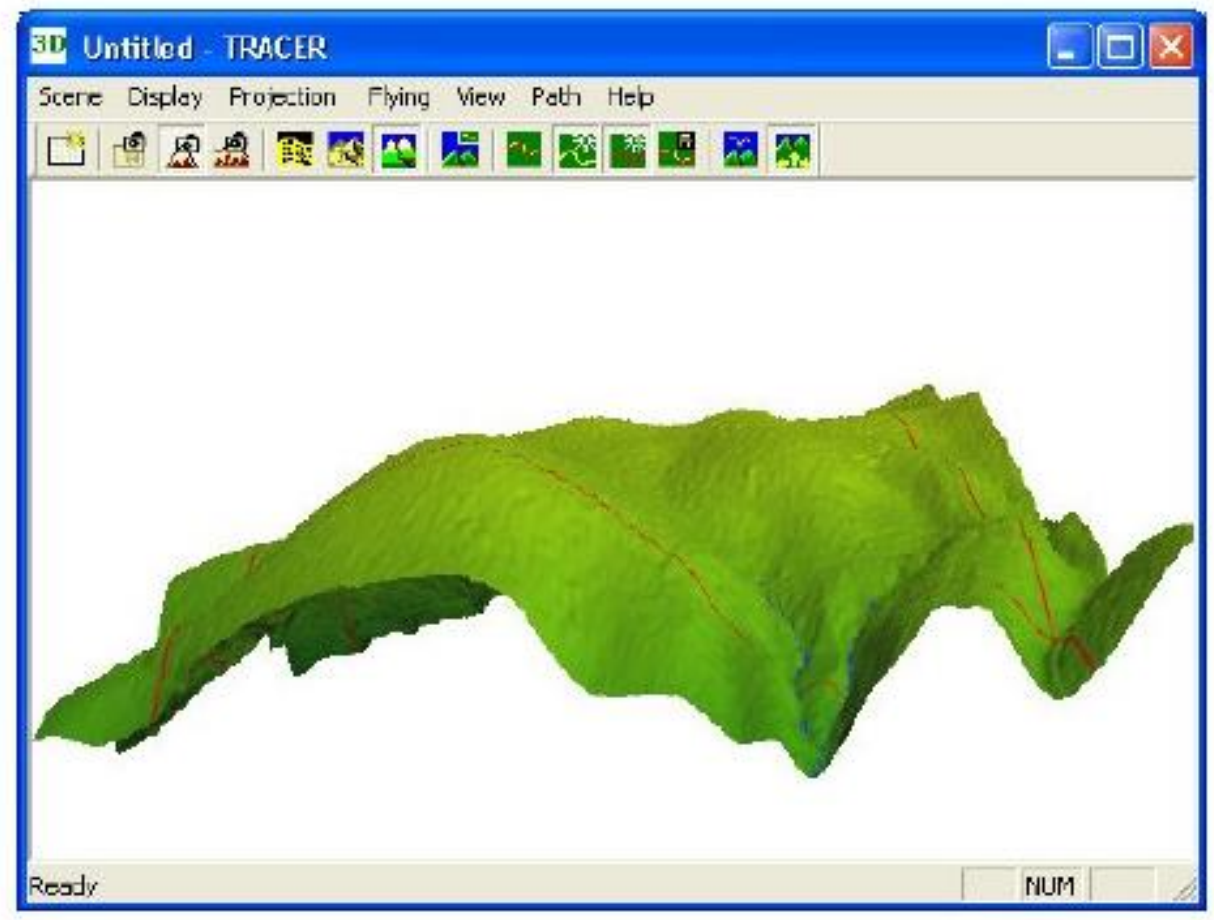

Figure 3.Displaying 3D image of the terrain 


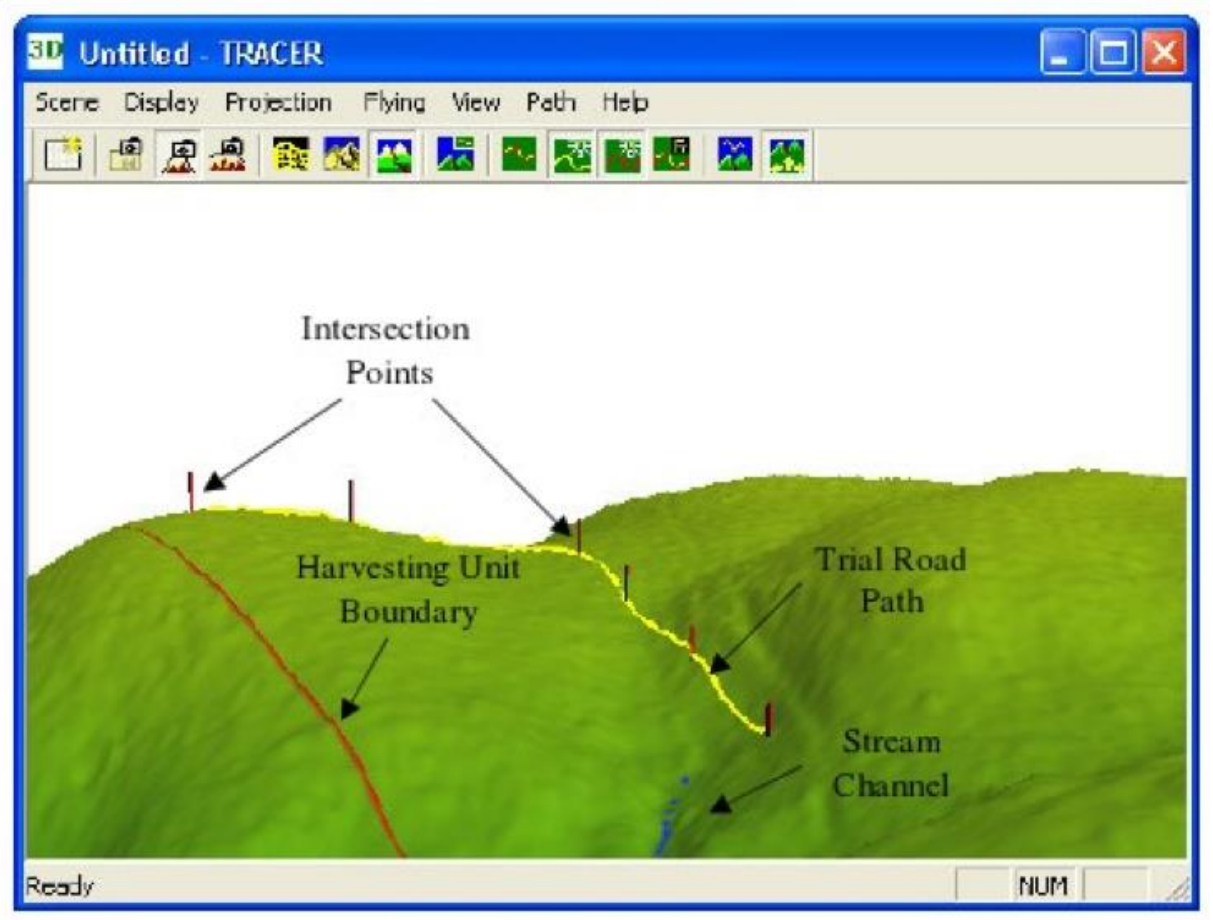

Figure 4. Selecting Points of intersection road path Trial

\section{Findings and discussions}

Three-dimensional (3D) city models, buildings, highways, parking areas bridges, such as all urban features and revitalizes. 3D city reconstruction with the computer platform helps to form a basis for rearranging existing city structures and this is important. The need to assist the future decision-making process and a 3D model show what will change and what will happen at the end of something new. 3D design visually explains the result of proposed changes. He convinces the authorities to make a useful decision.

Information about the 3D model and GIS infrastructure, which were created based on the database design, was updated. Each technique has been tested for usability, convenience, effectiveness and the most appropriate way of creating a $3 \mathrm{D}$ city.

Three-dimensional city models are often the definition of a land, streets, buildings and vegetation. Interest in 3D models has increased significantly in recent years. In fact, simulations are one of the main application areas for the propagation of electromagnetic waves. These simulations will be used for modeling.

Although there are operators for planning antenna locations, there may be an additional need in the future due to another need. 3D vehicle navigation systems are emerging as virtualized areas, virtual tourism information systems and visualization for the city, and building planning or architectural competitions. Many cities in the second and third world are rapidly expanding with strong urbanization. Due to the improvement of transport infrastructures, the high natural birth rates of rural migration, the expanding economies and the overall impact of globalization, these cities are rapidly increasing. Size and regional extension is required. Meanwhile, the planning remains mostly local and focused on the main urban area of a region, and urbanization is widely out of it. Development is faster than traditional maps. It is accurate enough to serve as the basis for planning and also these development dynamics are very strong, as the basis for traditional planning, maps are generally out of date or some cases are not available. 
However, current maps are necessary to control, control and guide these development trends. It provides a basis for urban and regional planning.

Thus, the 3D model is also a valuable tool for archaeological research. Research the topography in the first plan. Visibility and accessibility of historical sites are essential ideas, but much more interesting aspects. Static views of the 3D model can also serve as illustrations. All these researches have common points where a highly accurate $3 \mathrm{D}$ model is required to obtain reliable results.

Increasing the number of intersections can reduce driver safety and comfort due to frequent changes in the road class. However, the use of more intersection points will reduce the volume of land that leads to a significant reduction in the cost of space allocation and total construction cost, and the road profile becomes closer to the ground profile. The profile and plan view of the path alignment are shown in Figure 4 and Figure 5, respectively. The model required two horizontal curves along the path and one vertical vertical curve. The radiuses of the horizontal curves (eg $62.9 \mathrm{~m}$ and $50.9 \mathrm{~m}$ ) and the length of the vertical curve $(66.23 \mathrm{~m}$ ) are acceptable for safe traffic passage. The length of the road section was about $396 \mathrm{~m}$ with a gradient of about 2 to $12 \%$ (Figure 3 ).

The results indicated that total construction cost wast helargest cost component, followed by maintenance and transportation costs (Shape6). Within the construction cost components, surfacing cost was the largest, followed by earth work all ocation cost. Total cost of aintaining culverts and ditches and clearing bushes was the largest cost component of the maintenance costs.During the search process, the model calculated 147 feasible solutions out of 1200 automatically generated vertical alignment alternatives. The solution process took about 15 minutes. The most of the computation time was spent on calculating earth work all ocation using LP. The time spent on earth work all ocationin creases as the number intersection points along the road way increase.

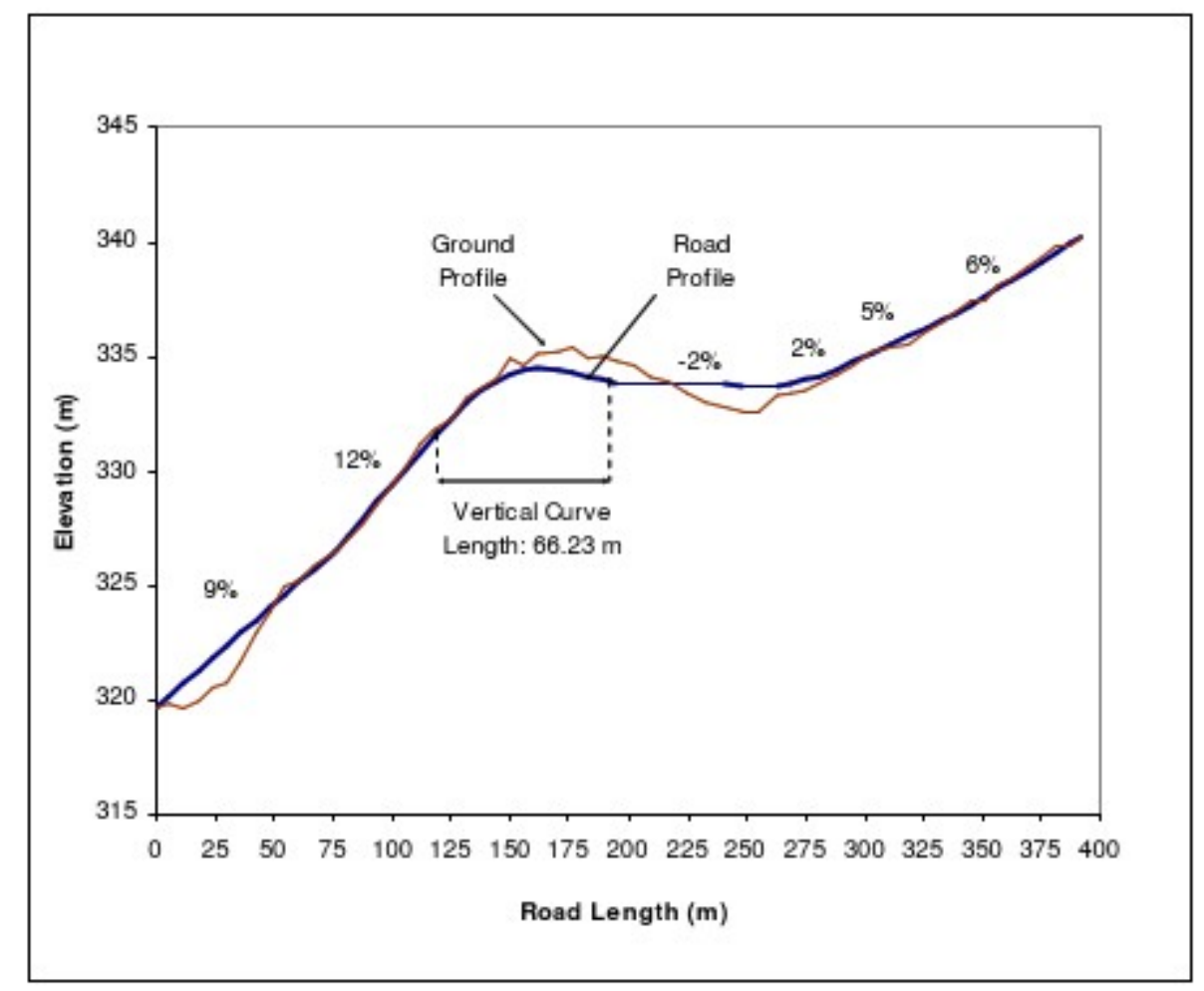

Figure 5. Profile view of the forest road 


\section{Conclusion and Recommendations}

It was observed that development was faster than even traditional maps. In order to be aware of the richness and needs of the cultural heritage, modeling has been a rapid solution. In most cases, information about larger roads can be found in planning projects. 3D city reconstruction with the computer platform helps to create a foundation for rearranging existing city structures, and saves time because it is important for the modeling project.

During the pre-engineering planning phase, the collaborating parties include municipalities, regional councils, environmental authorities and other planning organizations, landowners, local residents, entrepreneurs and various non-governmental organizations. Comprehensive interaction has been particularly important, especially in preengineering planning. Because the most important basic project solutions are decided at this stage. At the engineering planning stage, the interaction is mostly concerned with details and in addition to the municipalities, the parties include the land route, the residents and the entrepreneurs around the road. It serves as a tool to obtain the necessary information for planning. The aim of the interaction is to find acceptable solutions for all parties involved in the planning. Previously, the interaction begins at the planning stage, the better the results obtained. In this way, it is easier to consider various proposals and perspectives.

Planning of a transportation system includes interactive planning, land use and traffic. Thus, a framework has been created for the regulation of different traffic modes and land use. Planning produces traffic policy objectives, network plans for different traffic modes, application strategies for the system, and assessment of impacts. Pedestrian and bicycle traffic, public transportation, parking etc. It is understood that more detailed plans are needed. Road planning requires interactive cooperation in all stages of planning. The content of the Parties, scope and interaction depends on the planning phase and the nature of the project.

\section{References}

Egypt M., 2001. Multipurpose Forest Management Plans Based on Geographic Information Systems Purpose Programming Method (Forestry Planning Planning Example), PhD Thesis, KTU Graduate School of Natural and Applied Sciences, Trabzon.

Akay A.E., Erdas O., Belen B., 2006. Using GIS-Based Sediment Estimation Model, SEDMODL2 in Calculation of Sediment from Forest Roads. degerlendirilmesiçalısta made of forestation and erosion control applications in semi-arid regions of Turkey.

K. Altun L., Yilmaz M., Acar C., Turna, Baskent E.Z., and Bilgili E., 2003. Evaluatingtheseasonalchanges of waterquality of DegirmendereandGalyanRivers (Trabzon, Turkey). J. Of EnvironmentalBiology. 24 (4): 415-422. November 2006. Nevsehir.

Baskent E.Z., 2001. Combinatorialoptimization in forestecosystemmanagemen ,. TurkishJournal of AgricultureandForestry. (25): 187-194.

ETABS V13. computersandstructuresinc.

ACI 209R-08 (2008). Guide forModellingandCalculatingShrinkageandCreep in HardenedConcrete. AmericanConcreteInstitute, U.S.A.

Campbell, K. W. \& Bozorgnia, Y. (2008). NGA groundmotion model forthegeometricmeanhorizontalcomponent of PGA, PGV, PGD and 5\% dampedlinearelacticresponsespectraforperiodsrangingfrom 0.01 to 10s, Earthquake Spectra, 24

A. E. Akay I. R. Karas, J. Sessions, A. Yuksel, N. Bozali, R. Gundogan dUsing High-ResolutionDigitalElevation Model forComputer-AidedForest Road Design

https://www.buildings.com, 15.04.2018.

https://emlakkulisi.com/imar-plani-nedir/158452

https://polen.itu.edu.tr/bitstream/11527/15082/1/10064402.pdf 
https://www.google.com.tr/search?q=yeni+imar+plan\%C4\%B1+nas\%C4\%B11+yap\%C4\%B11\%C4\%B1r+tez\&t bm=isch\&tbo=u\&source=univ\&sa=X\&ved=0ahUKEwju8_LE_K_bAhWrIMAKHXZ4CxUQsAQIRw http://tok2013.inonu.edu.tr/assets/book/Bolum2-

Otomatik Kontrol Ulusal Toplantıs1, TOK2013, 26-28 Eylül 2013

http://galeri3.arkitera.com/var/albums/Urun/2012/Duravit_10/02.jpg

http://galeri3.arkitera.com/var/albums/Urun/2012/Duravit_10/03.jpg 